\title{
Influence of fatigue on the nanohardness of NiTiCr-wires
}

\author{
M. Frotscher ${ }^{1 \mathrm{a}}$, M. L. Young ${ }^{1}$, H. Bei ${ }^{2}$, E. P. George ${ }^{2,3}$, K. Neuking ${ }^{1}$ and G. Eggeler $^{1}$ \\ ${ }^{1}$ Ruhr-University Bochum, Institute for Materials, Universitätsstr. 150, 44801 Bochum, Germany \\ ${ }^{2}$ Materials Science and Technology Division, Oak Ridge National Laboratory, Oak Ridge, Tennessee 37831, USA \\ ${ }^{3}$ Department of Materials Science and Engineering, University of Tennessee, Knoxville, Tennessee 37996, USA
}

\begin{abstract}
Testing parameters, such as rotational speed and bending radius, have a strong influence on the fatigue life of pseudoelastic NiTi shape-memory alloys during bending rotation fatigue (BRF) experiments [1, 2]. Previous studies showed a decrease in the fatigue life for smaller bending radius (i.e. higher equivalent strain) and larger rotational speed. This observation is associated with an increase of dislocation density, the stabilization of stressinduced martensite during cycling, and an increase of the plateau stresses due to self-heating. In the present study, we examine the influence of these fatigue parameters on the nanohardness and shape recovery of pseudoelastic $\mathrm{NiTiCr}$ shape-memory alloy wires by nanoindentation. We show that nanoindentation is a suitable method for the characterization of fatigue-related microstructural changes, which affect the mechanical properties.
\end{abstract}

\section{Introduction}

NiTiCr alloys are of interest for medical applications because of their mechanical properties, especially their high torqueability and stiffness [3]. The addition of $\mathrm{Cr}$ leads to an increase of the yield stress and results in a strengthening of the alloy $[4,5]$. There is very little published literature $[6,7]$ about this ternary shape memory alloy (SMA), although the material is used as a structural material in medicine, e.g. for guide wires. In the present work, the mechanical properties of NiTiCr wires were characterized by nanoindentation after bendingrotation fatigue (BRF) experiments at varying strain amplitudes and rotational speeds. Previous work showed that the material undergoes a two-step martensitic transformation from B2 to R-phase and from R-Phase to B19' upon cooling $[2,8]$. The main interest of this study was to examine, whether changes in the microstructure and macroscopic mechanical properties due to fatigue also affect the small-scale mechanical properties of SMA.

\section{Experiments}

Straight annealed and mechanically polished pseudoelastic NiTiCr wire were purchased from Memry GmbH (Weil am Rhein, Germany). Some of these wires were solution annealed at $850^{\circ} \mathrm{C}$ for $15 \mathrm{~min}$ in an $\mathrm{Ar}-$ environment using a Käsermann + Spérisen/SOLO model 111-13/10/30 furnace and then subsequently waterquenched. As-received pseudoelastic NiTiCr wires with a diameter of $1.2 \mathrm{~mm}$ were subjected to BRF at a rotational speed of $\omega=800 \mathrm{~min}^{-1}$ and bending radii/strain rates of $R=30-60 \mathrm{~mm} / \varepsilon_{a}=1-2 \%$, as described in detail in Frotscher et al. [2]. Samples from fatigued wires were cut from the middle of the wires (i.e. location of highest stresses and strains during BRF) and cold-embedded in epoxy resin EMS Araltide 502 and hardener Loctite Hysol HD3416 at a ratio of 10:1. The samples were then mechanically ground (up to 800 mesh), and auto-polished with an aluminum oxide suspension for 12 hours and, lastly, with a colloidal silica suspension for 24 hours using a Buehler type Vibromet 2 polishing machine.

Hardness measurements at room temperature $(294 \mathrm{~K})$ were performed using a MTS XP nanoindenter. All indentations were performed with a Berkovich indenter tip. The wires were tested along the wire axis in the middle and on the outer edge of the sample, to characterize the effects of the inhomogeneous stress- and strain distribution during BRF experiments. For good statistics, each specimen was indented with at least 3 by 6 and up to 12 by 12 indents at a distance of $25 \mu \mathrm{m}$ in the x-direction (i.e. along the wire axis) and $100 \mu \mathrm{m}$ in the ydirection (i.e. perpendicular to the wire axis). For a systematic comparison of pseudoelastic recovery during nanoindentation experiments, the remnant depth ratio (RDR) can be calculated as

\footnotetext{
${ }^{a}$ email : matthias.frotscher@gmx.de
}

This is an Open Access article distributed under the terms of the Creative Commons Attribution-Noncommercial License (http://creativecommons.org/licenses/by-nc/3.0/), which permits unrestricted use, distribution, and reproduction in any noncommercial medium, provided the original work is properly cited. 


$$
\mathrm{RDR}=\frac{h_{\text {rem }}}{h_{\text {max }}}
$$

where $h_{\text {rem }}$ and $h_{\max }$ are the remnant depth and maximum depth after unloading and during loading, respectively. Full pseudoelastic recovery is associated with a RDR close to zero [9]. The dependence of the nanohardness and RDR on the maximum indentation depth was examined by indenting as-received specimens to depths of 50 to $1,000 \mathrm{~nm}$. The nanohardness of wire specimens fatigued at different rotational speeds and bending radii/strain rates was compared at a nominal indentation depth of $d<500 \mathrm{~nm}$ and a peak hold time of $10 \mathrm{~s}$. In addition to the nanoindentation tests on wires with a diameter of $1.2 \mathrm{~mm}$ that had been subjected to BRF at a rotational speed of $\omega=800 \mathrm{~min}^{-1}$ and bending radii/strain rates of $R=30-60 \mathrm{~mm} / \varepsilon_{a}=1-2 \%$, nanoindentation tests were also performed on NiTiCr wires of 1.2 and $1.4 \mathrm{~mm}$ diameter, which had been subjected to BRF at a rotational speed of $200 \mathrm{~min}^{-1}$. In order to compare the samples at the same equivalent strains, the corresponding bending radii $\mathrm{R}$ were calculated according to Wagner [10].

\section{Results and Discussion}

Fig. 1a shows nanohardness as a function of maximum indentation depth for the as-received material. Each data point represents the average of 20 measurements. As seen in Fig. 1a, nanohardness decreases with increasing indentation depth. An indentation size effect is observed, with the nanohardness increasing more sharply at maximum indentation depths below $400 \mathrm{~nm}$. This could be due to stress-induced martensite variants being of the same order of magnitude as the indentation depth. Above this threshold, nanohardness decreases nearly linearly. An average nanohardness of $3.85 \mathrm{GPa}$ was observed for a maximum indentation depth of $500 \mathrm{~nm}$. This value is used to compare with the fatigued material.

As illustrated in Fig. 1b, the RDR is plotted as a function of the maximum indentation depth, where each data point represents the average of 10 measurements with error bars indicating the standard deviation. It can be seen that the recovery is higher at lower indentation depth. Beyond a maximum indentation depth of about 400 $\mathrm{nm}$, the recovery continues to decrease with increasing depth; however, the slope is constant. This can be attributed to the fact that only a certain amount of the total deformation is recovered upon unloading (i.e. the size of the indent during the experiment is larger than the remaining indent). This observation is in good accordance with data obtained for NiTiFe SMA, where transmission electron microscopy (TEM) results show the formation of stress-induced martensite in front of the indenter tip and the creation of a high dislocation density during nanoindentation [11]. The partial reversibility is associated with reversible martensitic transformations, while the accumulation of irreversible strain and the stabilization of stress-induced martensite are attributed to dislocations.

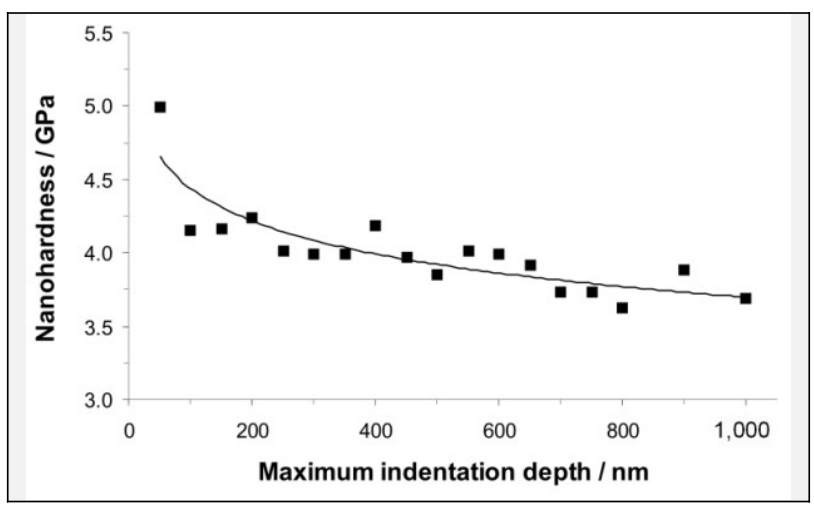

a)



b)

Fig. 1. (a) Nanohardness and (b) remnant depth ratio (RDR) as a function of maximum indentation depth of pseudoelastic NiTiCr-wire (as-received condition).

The load-displacement curves presented in Fig. 2 show distinct pseudoelastic features, although residual deformation can be observed in all suggesting that plasticity occurs in the experiment even at very small loads. 
The nanoindentation results obtained near the outer edge of the wires show a stronger response than in the middle, due to higher equivalent strains during the fatigue experiments. Therefore, all data of fatigued samples shown here were measured near the outer edge. Fig. $2 \mathrm{~b}$ compares the load-displacement curves of NiTiCr wires fatigued at strains of $1 \%$ (black) and $2 \%$ (red) with the as-received (blue) and the solution annealed condition (green). Each curve represents the average value of at least 6 individual indentations. There is only a slight difference of about $3 \mathrm{mN}$ between the average maximum loads $(\sim 20 \mathrm{mN})$ of the as-received material and the sample fatigued at $1 \%$ strain. The shape of the load-displacement curves exhibits similar mechanical behavior. It should be noted that a NiTiCr wire strained to $1 \%$ is at the very beginning of its stress-strain plateau [2]. Therefore, the material is still in the austenitic phase, although a small amount of R-phase is now present which is stabilized by the small residual strain (dislocations) remaining after fatiguing. For the sample fatigued at $2 \%$ strain, the average maximum load is approximately $9 \mathrm{mN}$. In addition, the slopes of the curves are less steep. At this strain level, the material is well within the stress-strain plateau, where the formation of stress-induced martensite occurs [2]. In the solution annealed condition, the average maximum load of the NiTiCr wire is about $4.5 \mathrm{mN}$ and the slopes are almost linear.

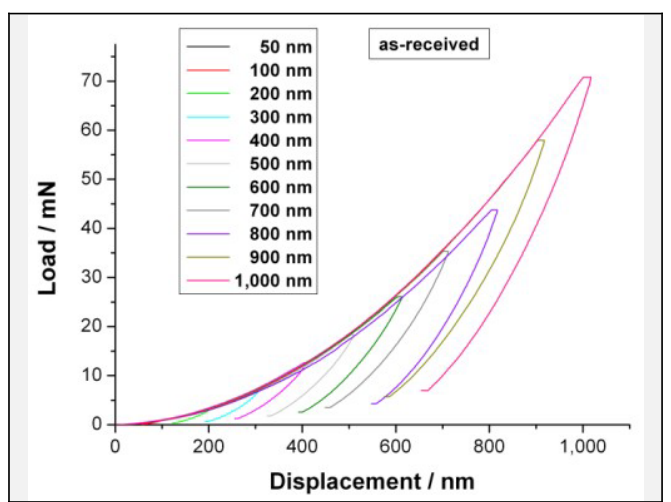

a)

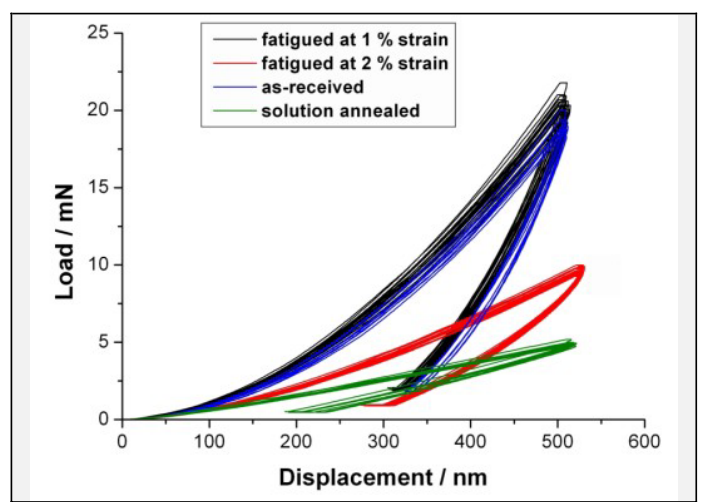

b)

Fig. 2. (a) Load-displacement curves from nanoindentation experiments on pseudoelastic NiTiCr wire with maximum indentation depths ranging from 50 to $1,000 \mathrm{~nm}$ (as-received condition) and (b) Comparison of the load-displacement curves for a maximum indentation depth of $500 \mathrm{~nm}$ on as-received, solution annealed, and fatigued ( 1 and $2 \%$ strain) $\mathrm{NiTiCr}$ wires.

Fig. 3a compares the nanohardness of as-received fatigued material ( 1 and $2 \%$ strain) with that of as-received and solution annealed materials. Although there is no significant difference between the as-received samples and those fatigued at $1 \%$ strain, the nanohardness of the fatigued material is slightly higher, probably due to an increase in the dislocation density during cyclic loading (i.e. plasticity). This result suggests that the equivalent strain in the bent wires during fatigue at $1 \%$ strain is too small to lead to the formation of stabilized, stressinduced martensite. The nanohardness of samples fatigued at $2 \%$ strain is considerably lower, which indicates that some stabilized, stress-induced martensite is present after cycling (i.e. the fatigue strains were large enough to be within the pseudoelastic plateau). This conclusion is supported by previous microstructural observations of pseudoelastic NiTi, where areas of stabilized martensite were found after fatigue experiments [12]. Dislocations may account for the stabilization of stress-induced martensite in some of the ultrafine grains within the microstructure, preventing their reverse transformation back to austenite upon unloading. Furthermore, it has already been shown that indenting a pseudoelastic, austenitic SMA can result in the formation of stress-induced martensite [11]. Based on previous results, it is known that the NiTiCr wires examined here contain a small volume fraction of titanium carbides [8]. Incidental indentation of these particles may contribute to some of the scatter in the indentation data. As illustrated in Fig. 3b, the RDR of the material fatigued at $1 \%$ strain is quite similar to that of the as-received material; however, the solution annealed samples show the highest recovery with an RDR close to 0.4 . The recovery of wires fatigued at $2 \%$ strain is somewhere in between that of the asreceived and the solution annealed materials $(\mathrm{RDR}=0.57)$. It is not surprising that the wires examined in this study have a remnant depth ratio larger than zero, because full pseudoelastic recovery is rarely reported in the literature for indentation studies [9, 11].

Although nanoindentation was performed as close to the fracture surface as possible, no clear dependence of the nanohardness or RDR on the distance from the fracture surface of the fatigued wires is observed. Most likely, plasticity at the very edge of the fracture surface affects both of these properties. 


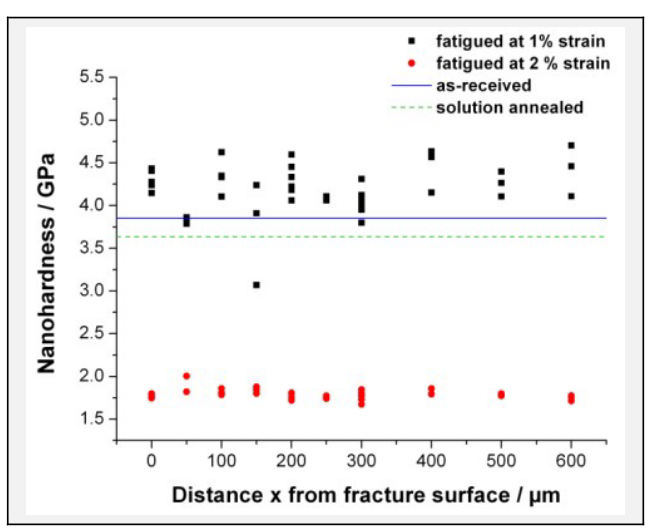

a)

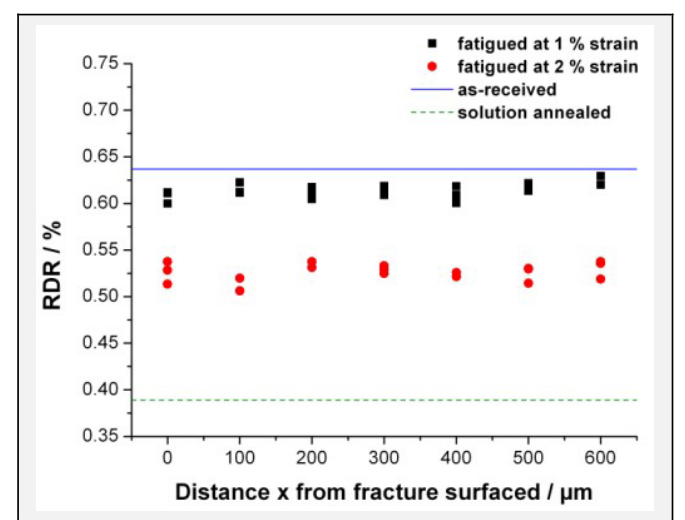

b)

Fig. 3. Comparison of (a) nanohardness and (b) remnant depth ratio as a function of distance from the fracture surface of pseudoelastic NiTiCr-wire fatigued at 1 and $2 \%$ strain $\left(\omega=800 \mathrm{~min}^{-1}\right)$ and in the as-received and solution annealed condition.

In the second part of this study, the influence of wire diameter was examined since it is known to have a strong influence on fatigue life during BRF experiments, because the defect probability and self-heating are higher in a larger volume $[1,2]$. Fig. 4a compares the nanohardness of wires with two different diameters $(1.2 \mathrm{and} 1.4 \mathrm{~mm})$ fatigued at $1 \%$ equivalent strain at a rotational speed of $200 \mathrm{~min}^{-1}$. It can be seen that the average nanohardness of the thicker wire is about $0.5 \mathrm{GPa}$ higher than that of the thinner wire. Doubling the equivalent strain to $2 \%$ (Fig. 4b) increases the average nanohardness of the thinner wire, while the value measured for the thicker wire stays at the same level. None of the tested wires had a nanohardness that could be associated with the presence of stabilized, stress-induced martensite. Therefore, it is likely that the differences in nanohardness are related to plasticity. Two possible explanations for these observations are as follows: (1) In a thicker wire, the larger volume results in a decreased heat transfer due to the higher energy that needs to be dissipated. As a result, selfheating during fatigue cycling increases, leading to higher inner stresses and subsequent lower fatigue life. (2) Another mechanism involved could be strain hardening. A thinner wire experiences larger deformation during cold working and subsequently has a smaller grain size, which is generally associated with higher strength. Further experiments at different strains are needed to better understand this mechanical behavior.

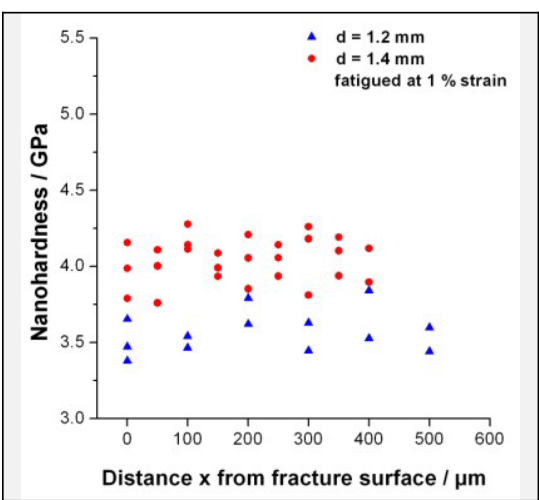

a)

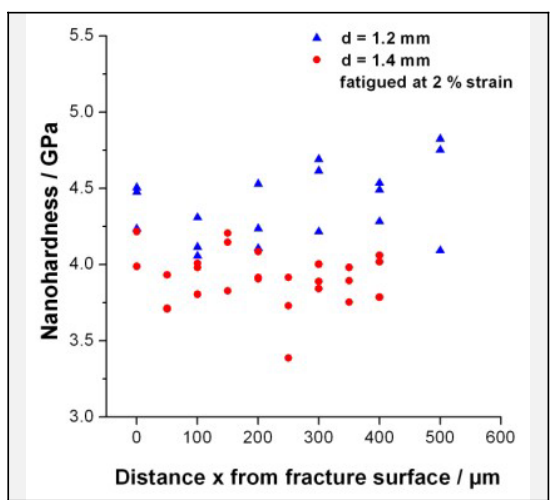

b)

Fig. 4. Influence of the wire diameter $d$ on the nanohardness of NiTiCr-wires fatigued at (a) $1 \%$ and (b) $2 \%$ equivalent strain $\left(\omega=200 \mathrm{~min}^{-1}\right)$.

\section{Conclusions}

In the present study, nanoindentation is used to characterize fatigue-related changes in the mechanical properties of NiTiCr wires. From the results obtained, the following conclusions can be drawn: 
(1) The nanohardness and shape recovery of NiTiCr-wires in the as-received condition decrease with increasing indentation depth. This behavior is more pronounced for maximum indentation depth below $400 \mathrm{~nm}$ and could be related to stress-induced martensite variants being of the same order of magnitude as the indentation depth.

(2) The load-displacement curves exhibit distinct pseudoelastic characteristics and it is shown that plasticity occurs during nanoindentation with a Berkovich indenter even at very small loads.

(3) Nanoindentation results obtained near the outer edges of the wires show a stronger response to fatigue than in the middle, because they experience higher equivalent strains during the fatigue experiments.

(4) The load-displacement curves of the as-received material and wires fatigued at $1 \%$ strain are very similar. In contrast, material fatigued at $2 \%$ strain features a much lower maximum load and a different load-displacement shape, because the wire is well within the stress-strain plateau and stabilized, stress-induced martensite is present. This observation is in accordance with previous work, where the presence of some areas with stabilized, stress-induced martensite after fatigue was reported in NiTi [13].

(5) A comparison of as-received, solution annealed, and fatigued NiTiCr-wires shows clear differences in nanohardness and shape recovery. These discrepancies can not be attributed to the indentation process alone. The nanohardness and shape recovery of the material fatigued at $1 \%$ strain are quite similar to those of the asreceived material. A small amount of R-phase is present after fatiguing due to small residual strain remaining, which results from dislocations stabilizing the R-phase. Some areas with stabilized, stress-induced martensite seem to be present after cycling at $2 \%$ strain. Probably, dislocations prevent the reverse transformation of some grains in the microstructure. Solution annealed samples show the highest recovery, while the recovery of wires fatigued at $2 \%$ strain is between the as-received and the solution annealed samples.

(6) No clear dependence of the nanohardness or shape recovery of fatigued wires on the distance from the fracture surface is observed.

(7) The wire diameter has an influence on the nanohardness. Thinner wires show an increase of nanohardness with increasing strain, while the nanohardness remains almost constant for thicker wires. Further work is required to clarify this behavior.

The authors acknowledge funding by the DFG (Deutsche Forschungsgemeinschaft) and the Land Nordrhein Westfalen through project B11 of the Collaborative Research Center SFB 459 (Shape-Memory Technology). MF is grateful for funding by the Ruhr-University Research School. MLY is financially supported by the Alexander von Humboldt Foundation. Part of this research was sponsored at the Oak Ridge National Laboratory by the Division of Materials Sciences and Engineering, U.S. Department of Energy.

\section{References}

[1] M. F. X. Wagner: New aspects of bending rotation fatigue in ultra-fine-grained pseudo-elastic NiTi wires, Int. J. Mat. Res. 97 (2006), p. 1687-1696.

[2] M. Frotscher, J. Burow, M. F.-X. Wagner, P. Schön, K. Neuking, R. Böckmann, G. Eggeler: Thermomechanical processing, microstructure and bending rotation fatigue of ultra-fine grained NiTiCr-wires, Proceedings of the International Conference for Shape Memory and Superelastic Technologies (SMST 2007), Tsukuba, Japan, ASM International, (2008), p. 149-158.

[3] H. Hosonda, S. Hanada, K. Inoue, T. Fukui, Y. Mishima, T. Suzuki: Martensite transformation temperatures and mechanical properties of ternary NiTi alloys with off stoichiometric compositions, Intermetallics 6 (1998), p. 291-301.

[4] S. P. Dretler, P. D. Geragotelis: Entraining biological calculi, Entraining biological calculi US6620172 (2003).

[5] S. P. Dretler, P. D. Geragotelis: Medical retrieving device, Medical retrieving device EP1493393 (2005).

[6] J. Y. Choi, S. Nemat-Nasser: Effect of annealing and initial temperature on mechanical response of a Ni-Ti-Cr shape-memory alloy, Mat. Sci. Eng. A 432 (2006), p. 100-107.

[7] S. Nemat-Nasser, J. Y. Choi: Strain rate dependence of deformation mechanisms in a Ni-Ti-Cr shapememory alloy, Acta Mater. 53 (2005), p. 449-454.

[8] M. Frotscher, J. Burow, P. Schön, K. Neuking, R. Böckmann, G. Eggeler: Characterization of the mechanical properties of ultra-fine grained NiTiCr-wires, Materialwiss. Werkstofftech. 40 (1-2) (2009), p. 17-22.

[9] J. Pfetzing, A. Schaefer, C. Somsen, M. F.-X. Wagner: Nanoindentation of pseudoelastic NiTi shape memory alloys: Thermomechanical and microstrucural aspects, Int. J. Mat. Res. 100 (2009), p. 1-7.

[10] M. F.-X. Wagner: Ein Beitrag zur strukturellen und funktionalen Ermüdung von Drähten und Federn aus NiTi-Formgedächtnislegierungen. Maschinenbau, Band 4, Bochumer Universitätsverlag (2005), p. 19-67, 72-79, 91-111.

[11] H. Zheng, J. Rao, J. Pfetzing, J. Frenzel, C. Somsen, G. Eggeler: TEM observation of stress-induced martensite after nanoindentation of pseudoelastic Ti50Ni48Fe2, Scripta Mater. 58 (2008), p. 743-746. 
[12] M. Frotscher, P. Nörtershäuser, C. Somsen, K. Neuking, R. Böckmann, G. Eggeler: Microstructure and structural fatigue of ultra-fine grained NiTi-stents, Proceedings of BNM 2007, Ufa, Russia, Materials Science and Engineering: A 503 (2009), p. 96-98.

[13] M. Frotscher: Hochflexible Komponenten aus NiTi-Formgedächtnislegierungen für medizinische Anwendungen - Werkstoffwissenschaftliche Untersuchungen zu Werkstoffgefügen und mechanischen Eigenschaften. Berichte aus der Werkstofftechnik, Shaker Verlag (2009), p. 49-56, 80-93. 